\title{
Spectral Intensity Bioaerosol Sensor (SIBS): A new Instrument for Spectrally Resolved Fluorescence Detection of Single Particles in Real-Time
}

\author{
Tobias Könemann ${ }^{1}$, Nicole Savage ${ }^{2 a}$, Thomas Klimach ${ }^{1}$, David Walter ${ }^{1}$, Janine Fröhlich- \\ Nowoisky ${ }^{1}$, Hang Su${ }^{1}$, Ulrich Pöschl ${ }^{1}$, J. Alex Huffman ${ }^{2}$, and Christopher Pöhlker ${ }^{1}$ \\ ${ }^{1}$ Max Planck Institute for Chemistry, Multiphase Chemistry Department, P.O. Box 3060, \\ D-55020 Mainz, Germany \\ ${ }^{2}$ University of Denver, Department of Chemistry and Biochemistry, 2190 E. Iliff Ave., Denver, \\ Colorado 80208, USA \\ ${ }^{a}$ Now at Aerosol Devices Inc., 430 North College Avenue \# 430, Fort Collins, Colorado 80524, \\ USA
}

Correspondence to:

J. A. Huffman (alex.huffman@ du.edu) and C. Pöhlker (c.pohlker@mpic.de)

This file includes:

Supplementary Tables S1 to S2

Supplementary Figures S1 to S14 
1 Table S1. Summary of physical properties of Polystyrene latex spheres (PSLs) and 2 polystyrene-divenylbenzene particles (PS-DVB) used in this study. Stated properties are taken 3 from manufacturer information. SD: Standard deviation, RI: Refraction index at $589 \mathrm{~nm}$ and $4 \quad 25^{\circ} \mathrm{C}$.

\begin{tabular}{|c|c|c|c|c|c|c|c|c|}
\hline $\begin{array}{l}\text { Diameter } \\
(\mu \mathrm{m})\end{array}$ & SD $(\mu \mathrm{m})$ & Confidence & RI & Material & Color / Dye & $\lambda_{\mathrm{ex}} / \lambda_{\mathrm{em}}(\mathbf{n m})$ & Provider & $\begin{array}{l}\text { Catalog } \\
\text { code }\end{array}$ \\
\hline 0.3 & 0.0148 & $\mathrm{CV}=5.1 \%$ & 1.59 & PSL & Non-fluorescent & Non-fluorescent & Polysciences Inc. & 64015 \\
\hline 0.356 & 0.014 & $\mathrm{CV}=3.9 \%$ & 1.59 & PSL & Non-fluorescent & Non-fluorescent & Polysciences Inc. & 64016 \\
\hline 0.4 & 0.0073 & $\mathrm{CV}=1.8 \%$ & 1.59 & PSL & Non-fluorescent & Non-fluorescent & Thermo-Fisher & $3400 \mathrm{~A}$ \\
\hline 0.5 & 0.0079 & $\mathrm{CV}=1.6 \%$ & 1.59 & PSL & Non-fluorescent & Non-fluorescent & $\begin{array}{l}\text { Duke Scientific } \\
\text { Corporation }\end{array}$ & $3500 \mathrm{~A}$ \\
\hline 0.53 & N/A & N/A & 1.59 & PSL & $\begin{array}{l}\text { Plum Purple / } \\
\text { Proprietary }\end{array}$ & $360 / 420$ & Bangs Laboratories Inc. & FS03F \\
\hline 0.6 & 0.010 & $\mathrm{CV}=1.7 \%$ & 1.59 & PSL & Non-fluorescent & Non-fluorescent & Thermo-Fisher & $3600 \mathrm{~A}$ \\
\hline 0.7 & 0.0083 & $\mathrm{CV}=1.2 \%$ & 1.59 & PSL & Non-fluorescent & Non-fluorescent & Thermo-Fisher & $3700 \mathrm{~A}$ \\
\hline 0.8 & 0.0083 & $\mathrm{CV}=1 \%$ & 1.59 & PSL & Non-fluorescent & Non-fluorescent & Thermo-Fisher & $3800 \mathrm{~A}$ \\
\hline 0.9 & 0.0041 & $\mathrm{CV}=0.5 \%$ & 1.59 & PSL & Non-fluorescent & Non-fluorescent & Thermo-Fisher & $3900 \mathrm{~A}$ \\
\hline 1 & 0.010 & $\mathrm{CV}=1.0 \%$ & 1.59 & PSL & Non-fluorescent & Non-fluorescent & $\begin{array}{l}\text { Duke Scientific } \\
\text { Corporation }\end{array}$ & $4009 \mathrm{~A}$ \\
\hline 1.6 & 0.020 & $\mathrm{CV}=1.3$ & 1.59 & PSL & Non-fluorescent & Non-fluorescent & Thermo-Fisher & $4016 \mathrm{~A}$ \\
\hline 2 & 0.021 & $\mathrm{CV}=1.0 \%$ & 1.59 & PSL & Non-fluorescent & Non-fluorescent & Thermo-Fisher & $4202 \mathrm{~A}$ \\
\hline 2 & N/A & $\mathrm{CV}=<5 \%$ & 1.59 & PSL & $\begin{array}{l}\text { Red / Firefli }{ }^{\mathrm{TM}} \\
\text { Fluorescent Red }\end{array}$ & $542 / 612$ & Thermo-Fisher & R0200 \\
\hline 2 & N/A & $\mathrm{CV}=<5 \%$ & 1.59 & PSL & $\begin{array}{l}\text { Green / Firefli }{ }^{\mathrm{TM}} \\
\text { Fluorescent Green }\end{array}$ & $468 / 508$ & Thermo-Fisher & G0200 \\
\hline 2 & N/A & $\mathrm{CV}=<5 \%$ & 1.59 & PSL & $\begin{array}{l}\text { Blue / Firefli }{ }^{\mathrm{TM}} \\
\text { Fluorescent Blue }\end{array}$ & $\begin{array}{l}368,388,412 / \\
445,445,473\end{array}$ & Thermo-Fisher & B0200B \\
\hline 2.07 & 0.15 & N/A & 1.59 & PSL & $\begin{array}{l}\text { Plum Purple / } \\
\text { Proprietary }\end{array}$ & $360 / 420$ & Bangs Laboratories Inc. & FS05F \\
\hline 3 & 0.032 & $\mathrm{CV}=1.1 \%$ & 1.59 & PSL & Non-fluorescent & Non-fluorescent & Thermo-Fisher & $4203 \mathrm{~A}$ \\
\hline 4 & 0.04 & $\mathrm{CV}=1.0 \%$ & 1.59 & PSL & Non-fluorescent & Non-fluorescent & Thermo-Fisher & 4204A \\
\hline 4.52 & 0.15 & $\mathrm{CV}=3.0 \%$ & 1.59 & PSL & Non-fluorescent & Non-fluorescent & Polysciences Inc. & 17135 \\
\hline 5 & 0.6 & $\mathrm{CV}=11 \%$ & 1.59 & PS-DVB & Non-fluorescent & Non-fluorescent & Thermo-Fisher & DC-05 \\
\hline 7 & 0.7 & $\mathrm{CV}=10 \%$ & 1.59 & PS-DVB & Non-fluorescent & Non-fluorescent & Thermo-Fisher & DC-07 \\
\hline 8 & 0.8 & $\mathrm{CV}=10 \%$ & 1.59 & PS-DVB & Non-fluorescent & Non-fluorescent & Thermo-Fisher & DC-08 \\
\hline 10 & 0.9 & $\mathrm{CV}=9.2 \%$ & 1.59 & PS-DVB & Non-fluorescent & Non-fluorescent & Thermo-Fisher & DC-10 \\
\hline 15 & 1.8 & $\mathrm{CV}=11 \%$ & 1.59 & PS-DVB & Non-fluorescent & Non-fluorescent & Thermo-Fisher & DC-15 \\
\hline 20 & 1.7 & $\mathrm{CV}=8.9 \%$ & 1.59 & PS-DVB & Non-fluorescent & Non-fluorescent & Thermo-Fisher & DC-20 \\
\hline
\end{tabular}


6 Table S2. Summary of reference particles used within this study. All biofluorophores, iron 7 oxide $\left(\mathrm{Fe}_{3} \mathrm{O}_{4}\right)$, and carbon nanotubes were purchased from Sigma-Aldrich, St. Louis, MO, 8 USA. Ammonium sulfate was purchased from Fisher Scientific, Hampton, NH, USA.

\begin{tabular}{ll}
\hline Reference particles & CAS Nr. \\
\hline Bacteriochlorophyll & $17499-98-8$ \\
Chlorophyll $a$ & $479-61-8$ \\
Chlorophyll $b$ & $519-62-0$ \\
NAD & $606-68-8$ \\
Riboflavin & $83-88-5$ \\
Tryptophan & $73-22-3$ \\
$\mathrm{Tyrosine}^{\mathrm{Fe}} \mathrm{O}_{4}$ & $556-02-5$ \\
$\mathrm{Carbon}$ nanotubes & $1317-61-9$ \\
Ammonium sulfate & $308068-56-6$ \\
\hline
\end{tabular}


(a) DH-Mini (Deuterium-Halogen)

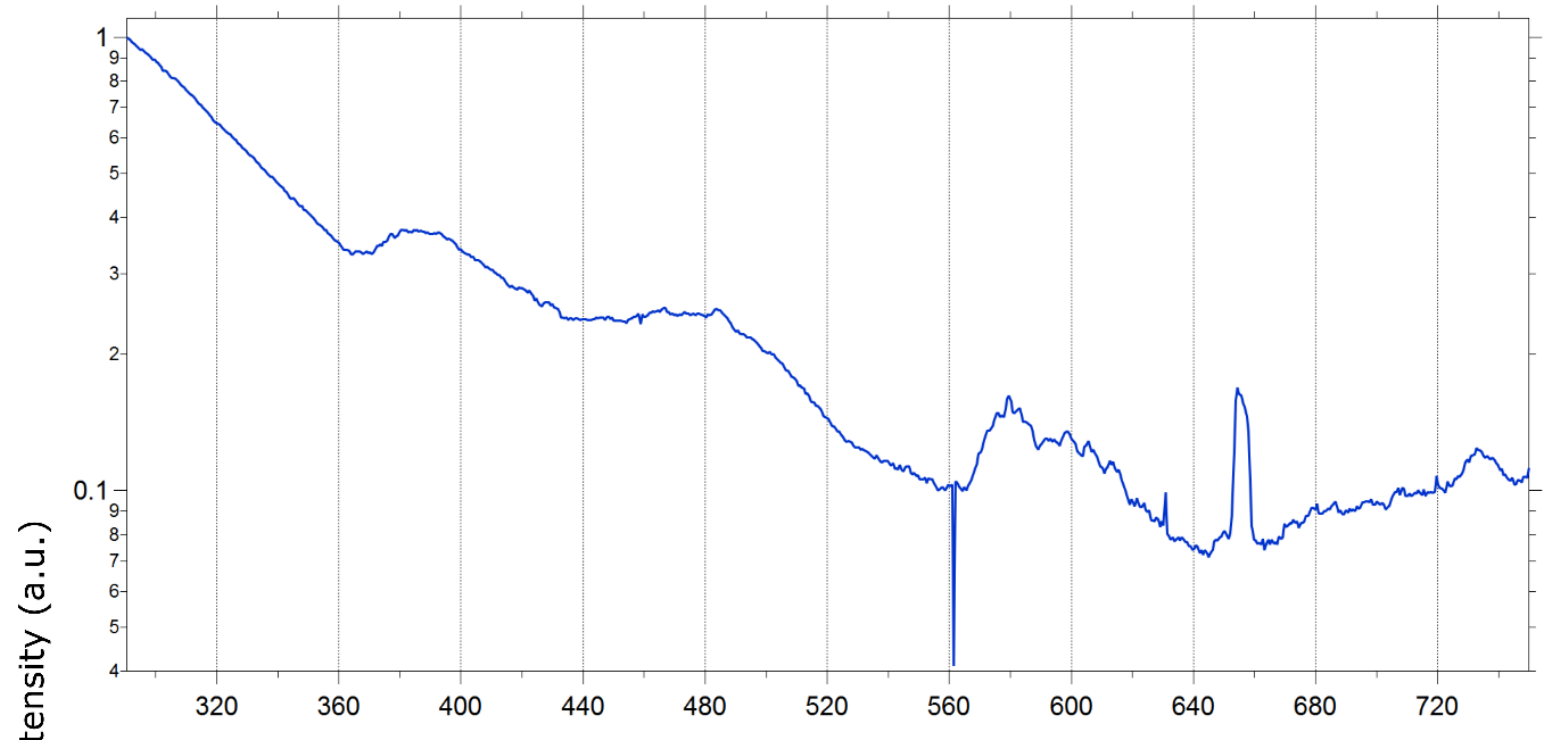

(b) EHJ (24 V, $250 \mathrm{~W})$ halogen projector lamp

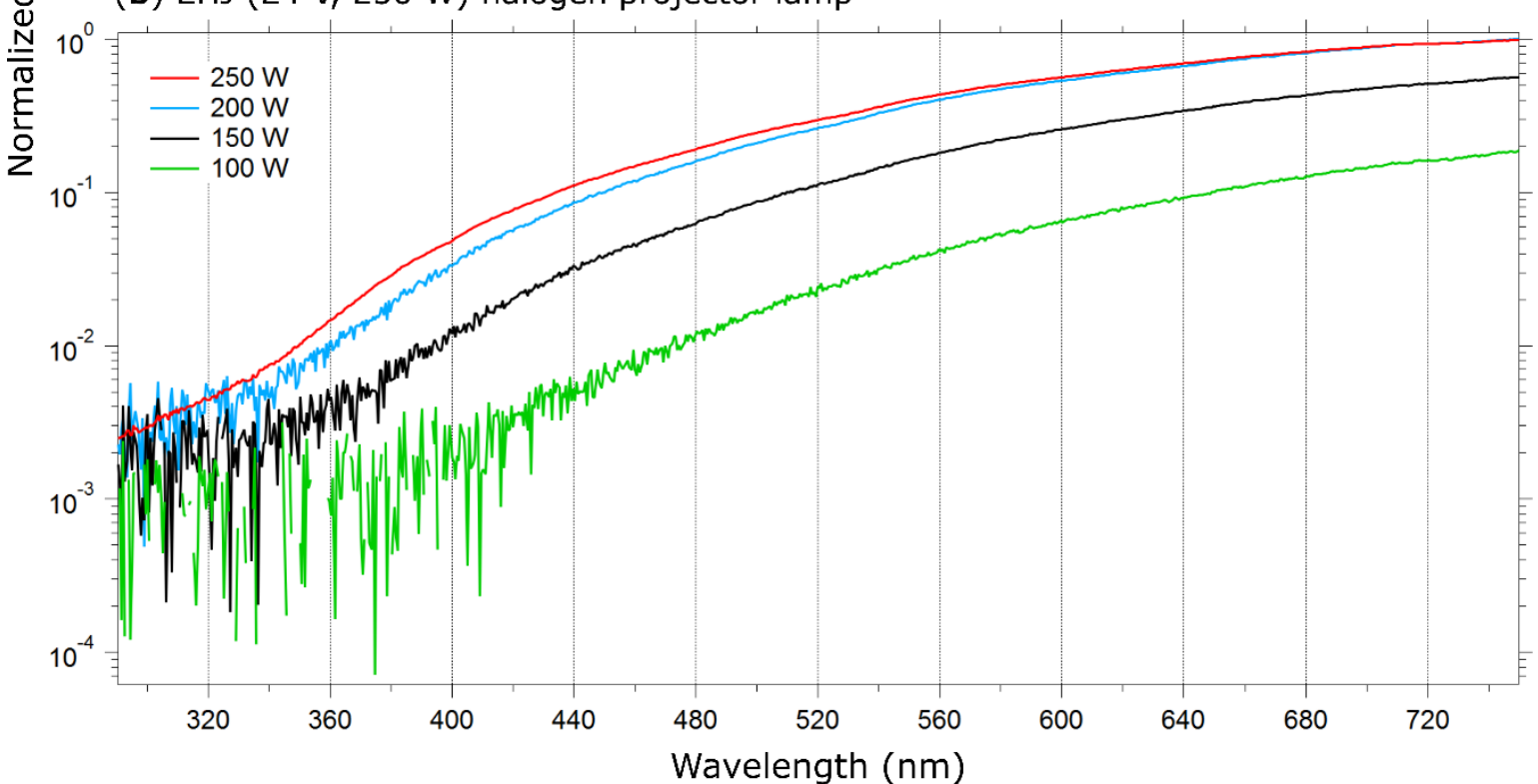

10 Figure S1. Normalized and averaged calibration lamp spectra. In (a), the spectrum of a

11 deuterium-halogen lamp (DH-Mini, Ocean Optics) is shown, in (b) the spectra of a halogen

12 projector lamp (EHJ 24V250W, Ushio), both measured with the Dual-FL spectrometer 13 (Horiba). 


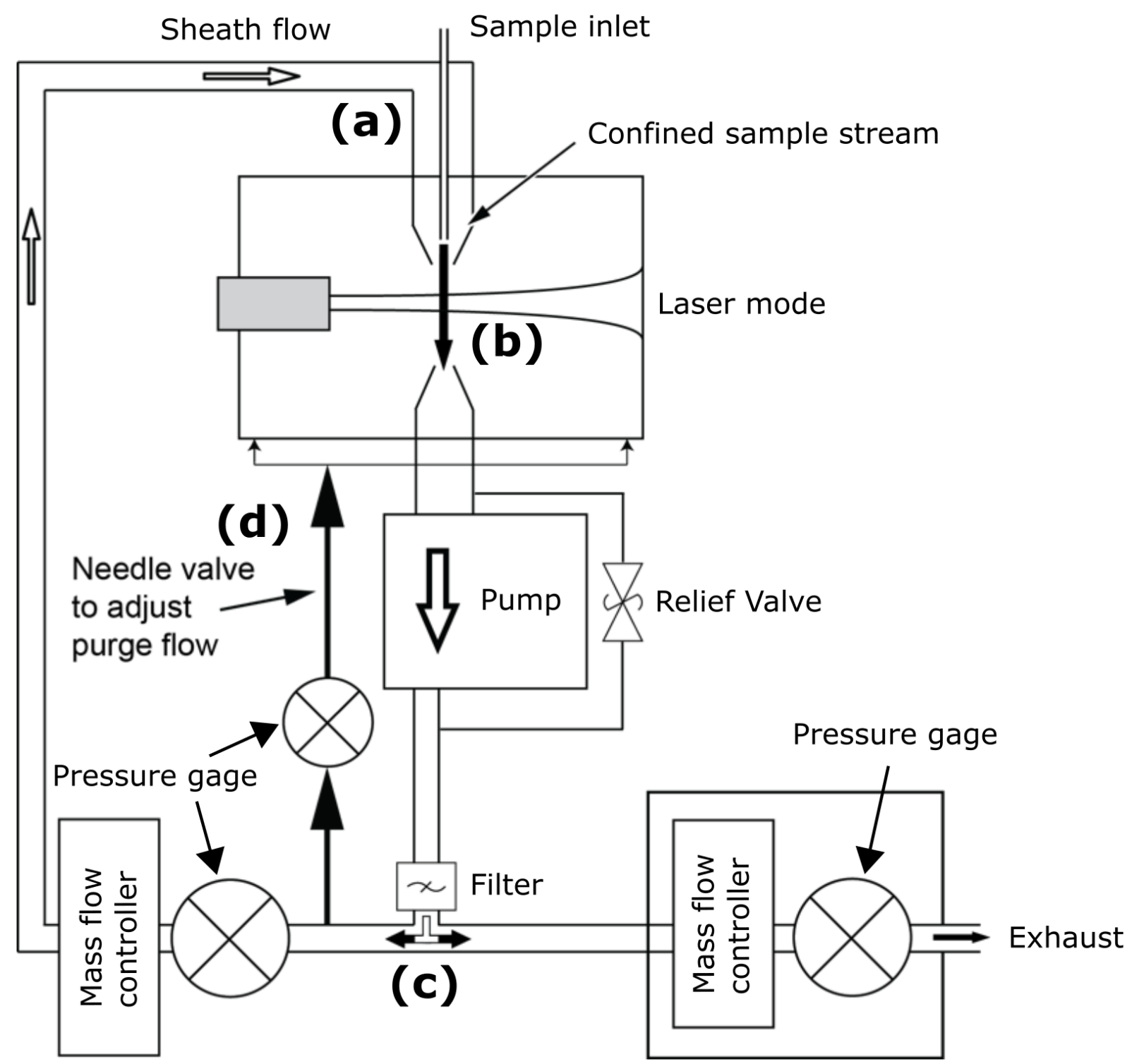

14 Figure S2. Flow diagram for the SIBS. Aerosol is drawn via a tapered delivery nozzle (a) into 15 the optical cavity. The intersection of sample flow and laser beam defines a sampling volume with approximately $0.7 \mathrm{~mm}$ in diameter and $130 \mu \mathrm{m}$ depth (b). The sheath flow is filtered 17 through a HEPA filter and recirculates in the system (c). A small purge flow, which is adjusted by a needle valve (d), constantly purges the optical cavity (Modified, image courtesy: DMT). 


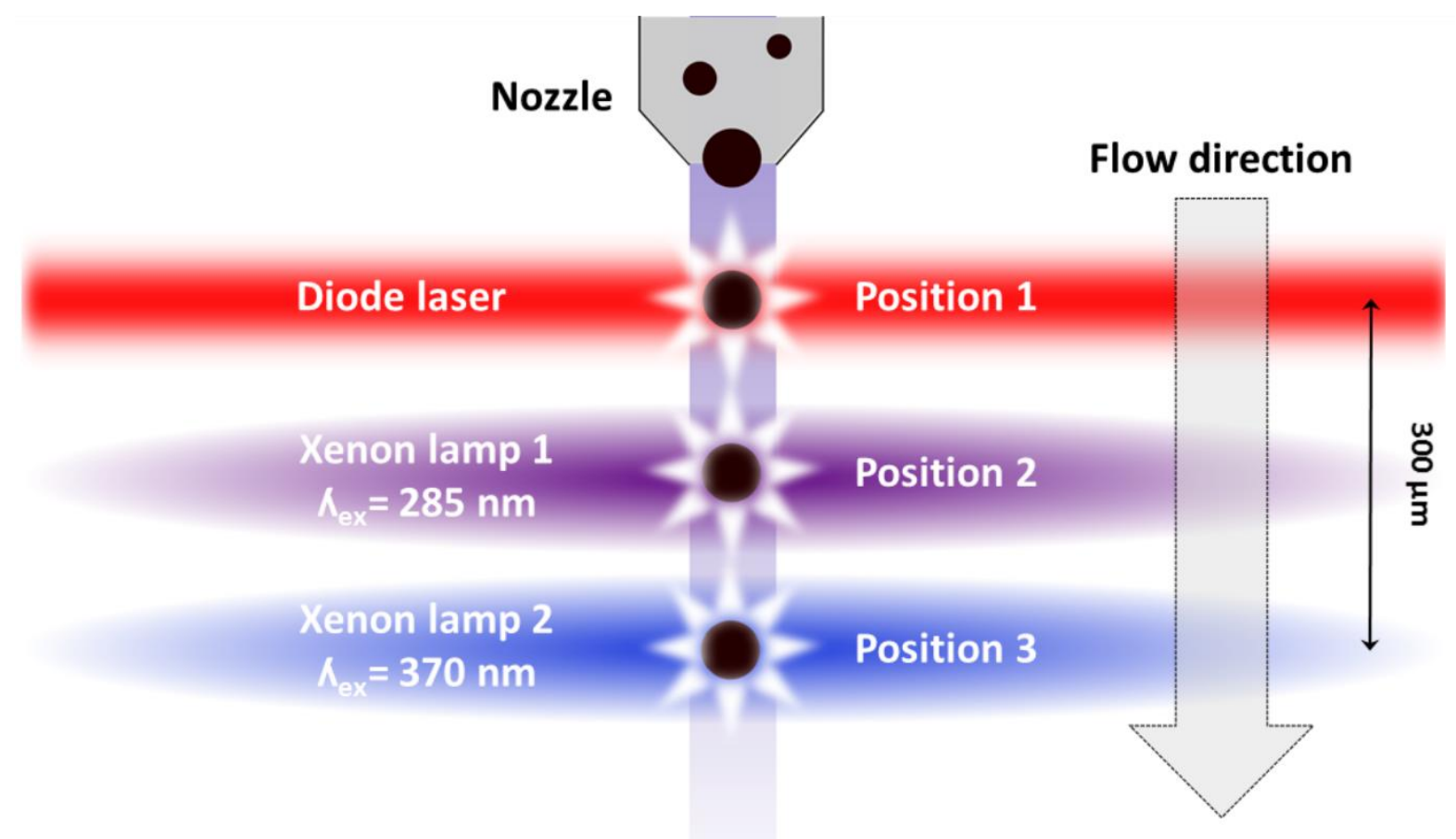

19 Figure S3. Schematic diagram of particle size and fluorescence detection. Position 1: Particles 20 scatter light in all directions after being illuminated by a diode laser $(\lambda=785 \mathrm{~nm})$. Position 2 : 21 Xenon lamp 1 is firing at $\lambda_{\mathrm{ex}}=285 \mathrm{~nm}$. Position 3: Xenon lamp 2 is firing at $\lambda_{\mathrm{ex}}=370 \mathrm{~nm}$. The 22 measurement cycle from position 1 to position 3 takes $\sim 25 \mu$ s over a distance of $\sim 300 \mu \mathrm{m}$. 23 (Modified, adapted from WIBS-4A service manual (DOC-0345 Rev A), DMT; 2012). 


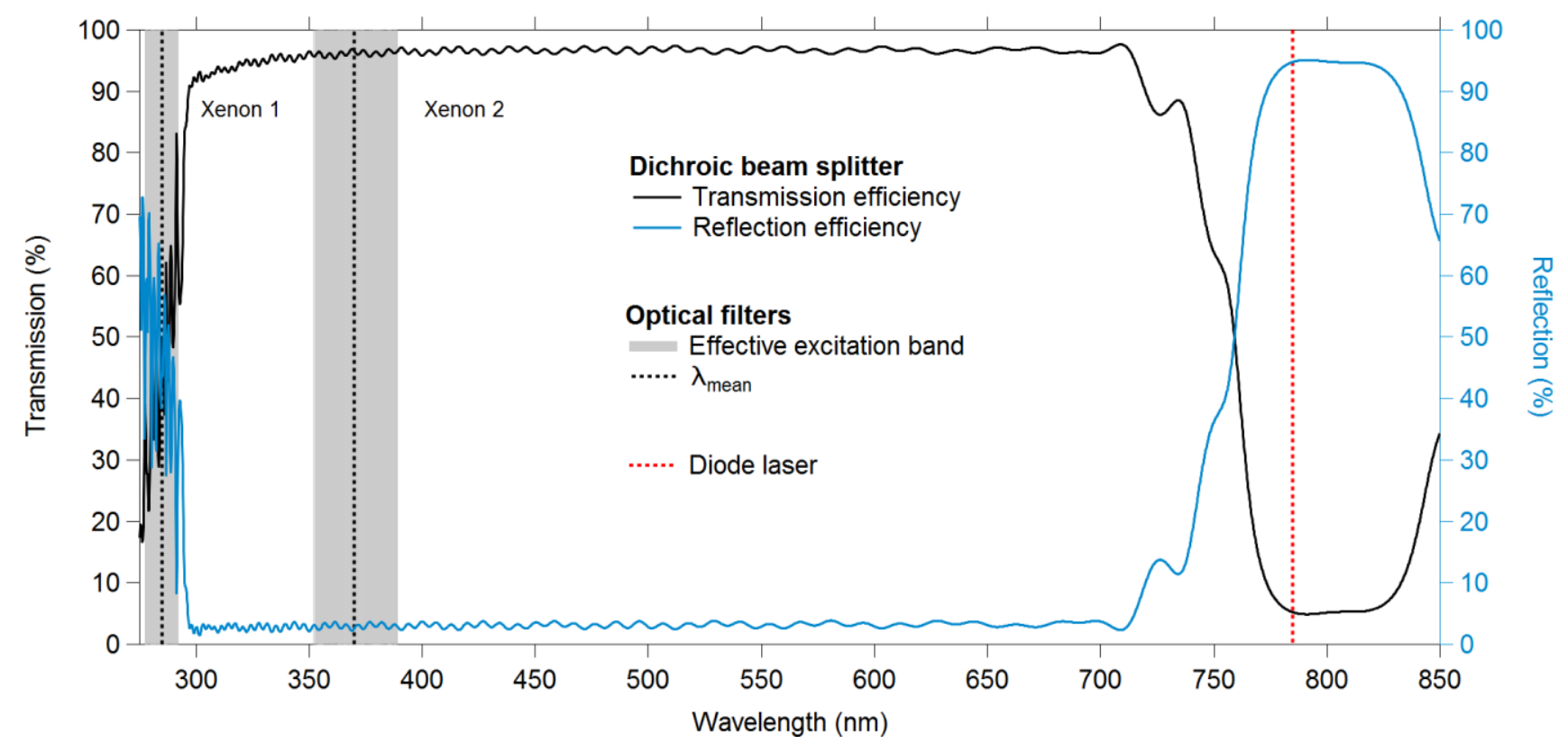

24 Figure S4. Transmission and reflection efficiency of the dichroic beam splitter. The beam

25 splitter transmits fluorescence emission (black line) to the grating polychromator and reflects

26 scattering light (blue line) to the particle sizing- and detection PMT. (Data courtesy: Semrock). 


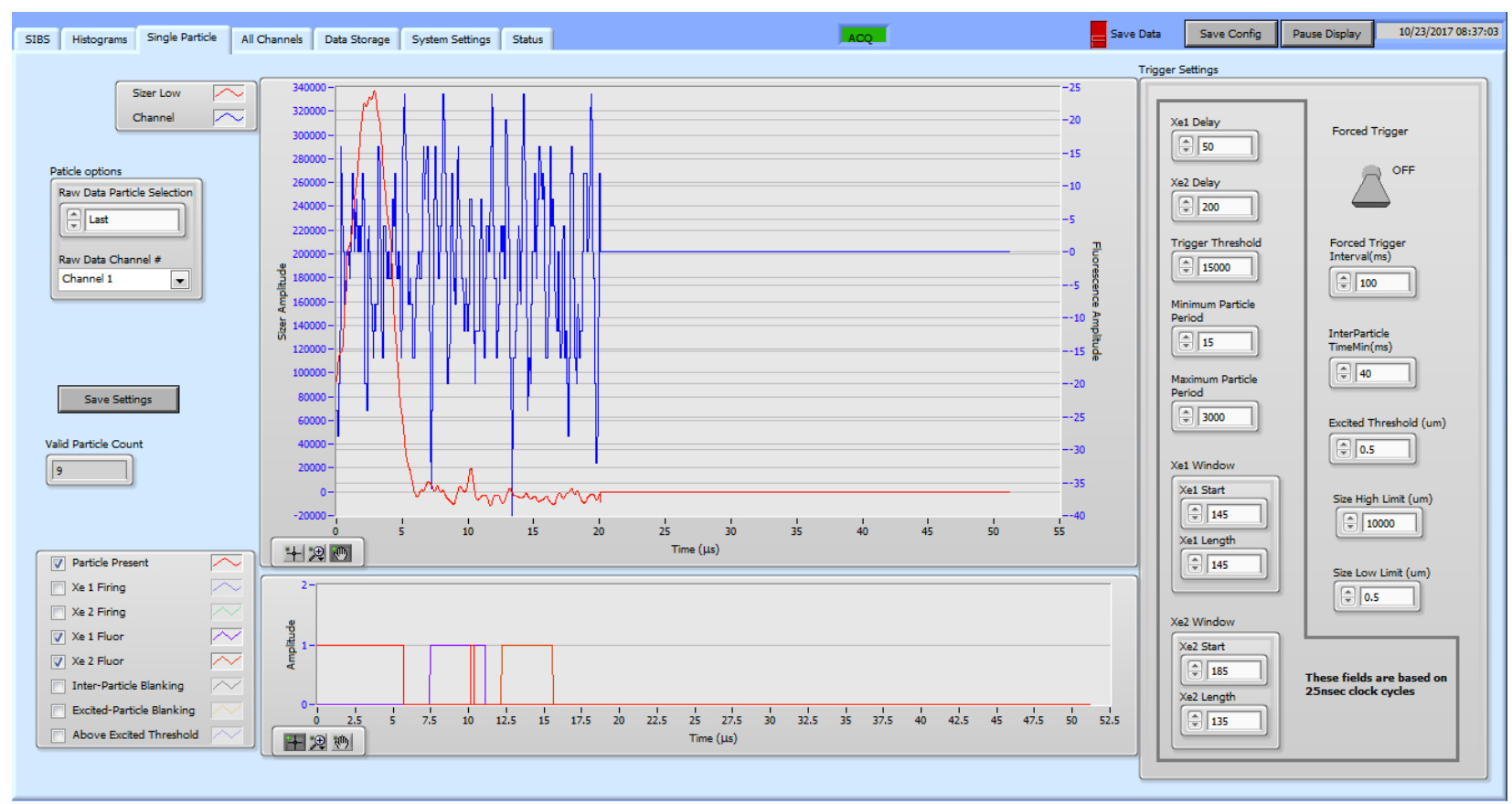

27 Figure S5. "Single Particle" tab of the SIBS user interface. 

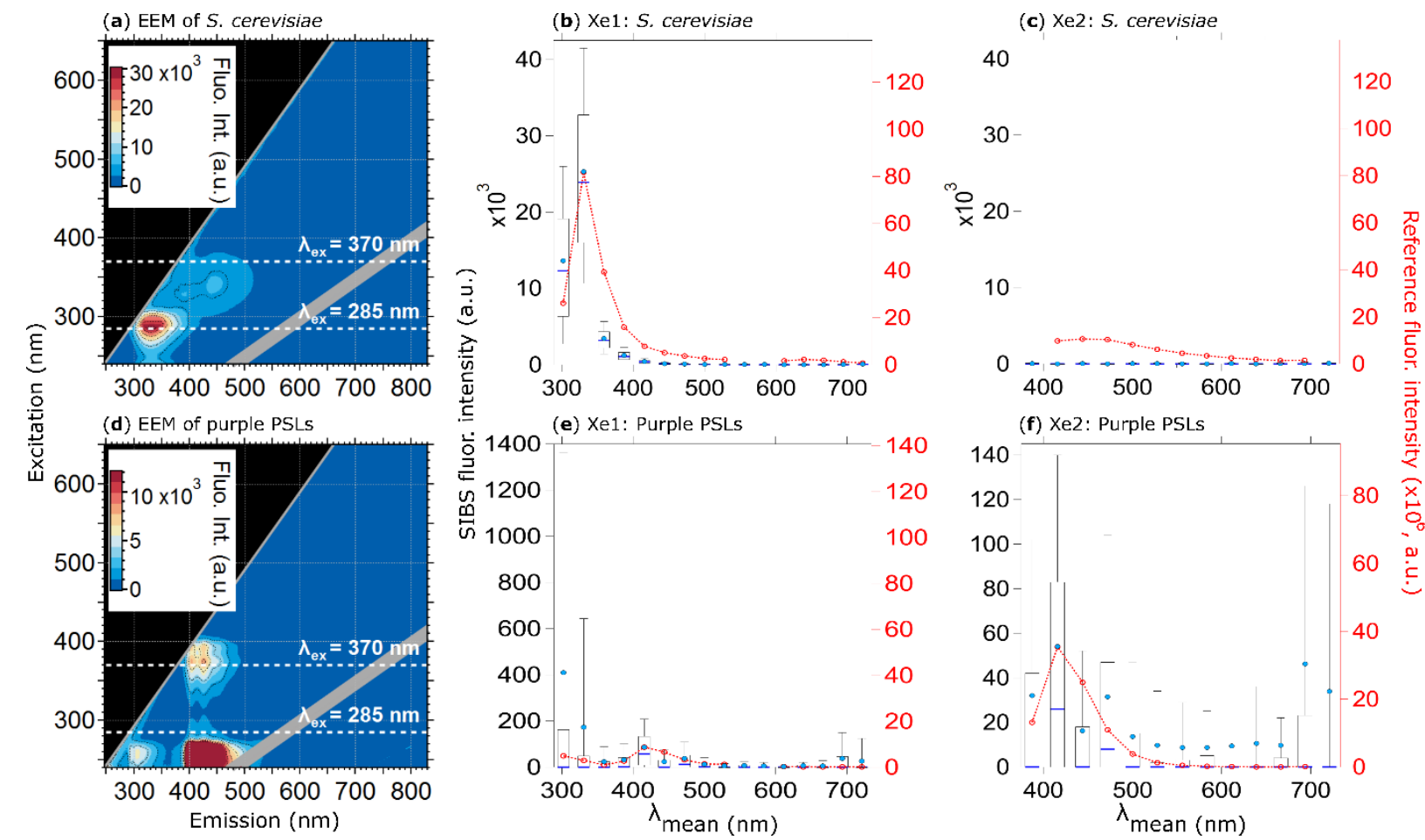

28 Figure S6. Corrected fluorescence emission of $S$. cerevisiae and $0.53 \mu \mathrm{m}$ purple PSLs. Steady-

29 state fluorescence signatures displayed as EEMs (left column) and spectra at Xe1 and Xe2

30 (middle, right columns) for: S. cerevisiae (a, b and c, size range between 4 - $10 \mu \mathrm{m}, 1057$

31 particles), and $0.53 \mu \mathrm{m}$ purple PSLs (d, e, and f, 5260 particles). Within EEMs: white dashed

32 lines show SIBS excitation wavelengths $\left(\lambda_{\mathrm{ex}}=285\right.$ and $\left.370 \mathrm{~nm}\right)$, grey diagonal lines indicate

$331^{\text {st }}$ and $2^{\text {nd }}$ order elastic scattering bands (both bands were subtracted automatically by the

34 Aqualog V3.6 software). 

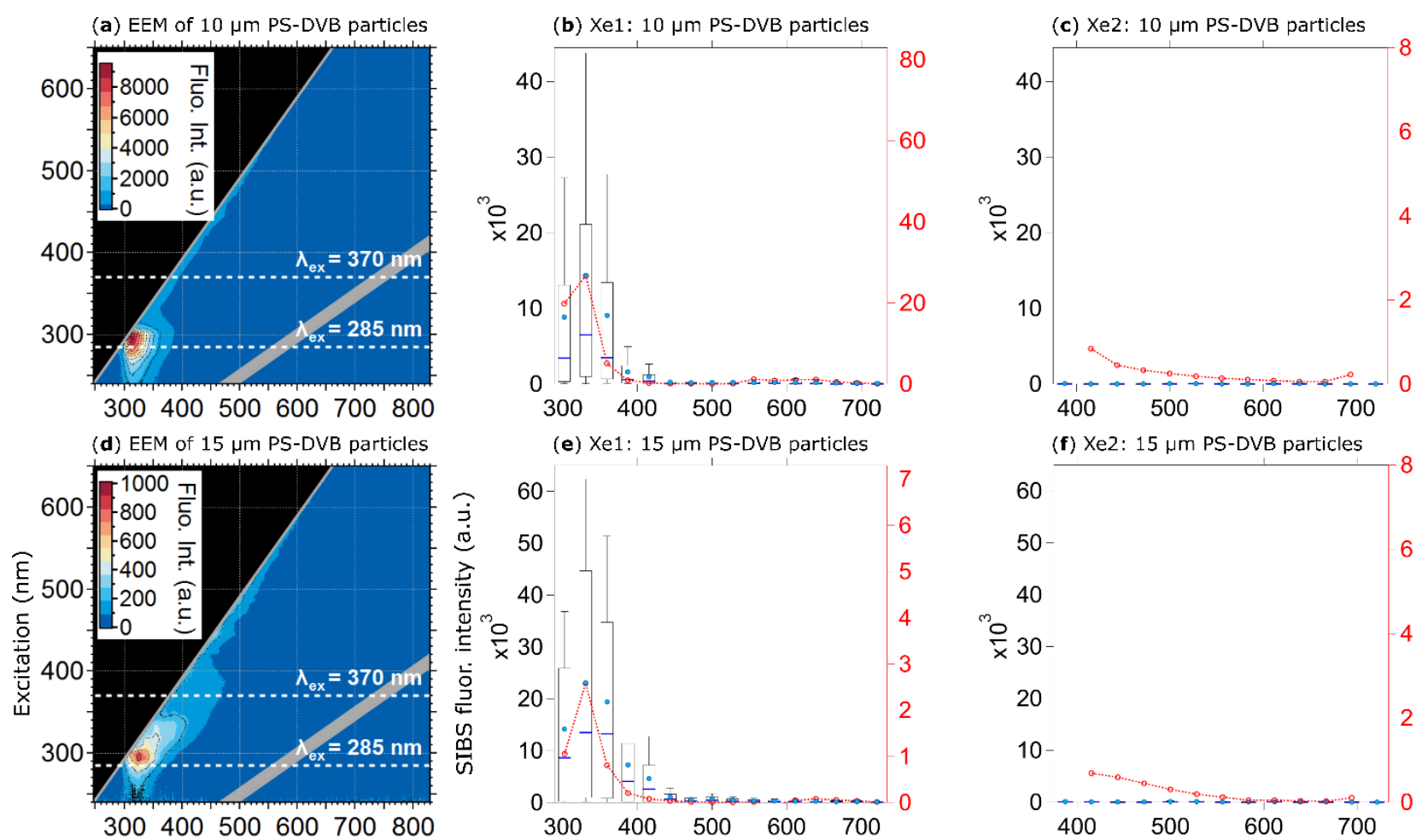

(e) Xe1: $15 \mu \mathrm{m}$ PS-DVB particles
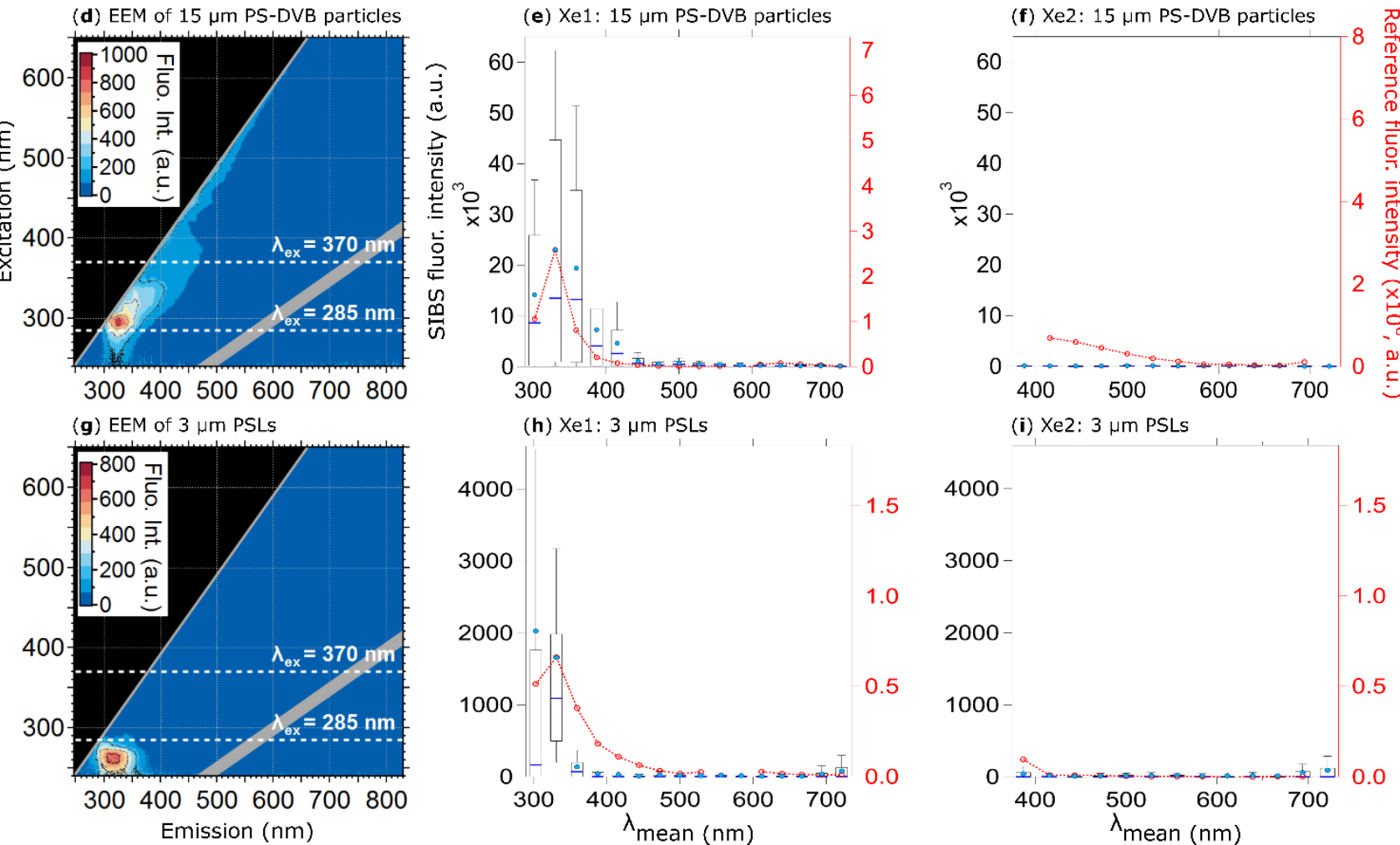

(h) Xe1: $3 \mu \mathrm{m}$ PSLs

(i) $\mathrm{Xe2:} 3 \mu \mathrm{m}$ PSLs
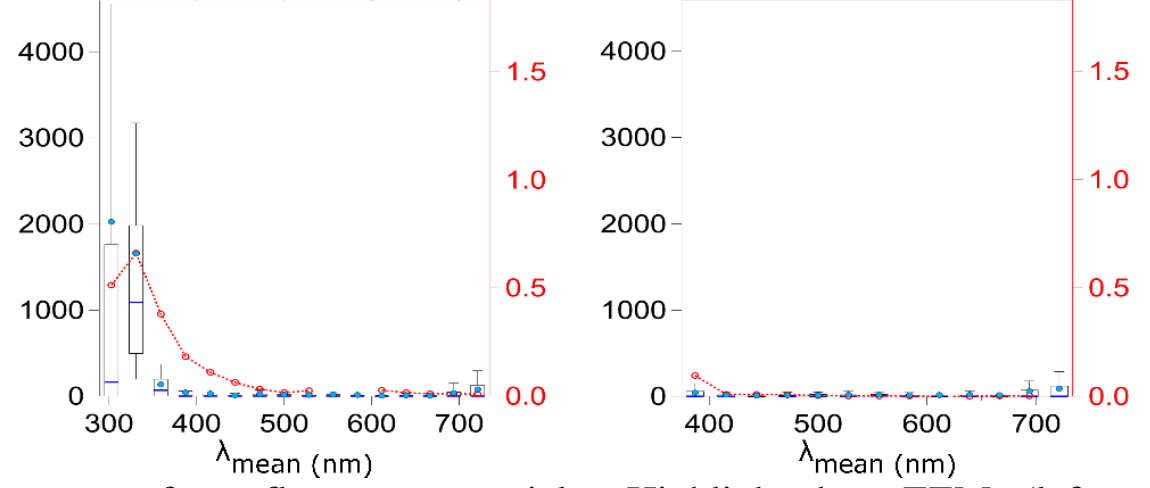

35 Figure S7. Fluorescence signatures of non-fluorescent particles. Highlighted are EEMs (left

36 column) and spectra at Xe1 and Xe2 (middle, right columns) for: $10 \mu \mathrm{m}$ (a, b, and c,

37 uncorrected, 367 particles) and $15 \mu \mathrm{m}$ (d, e, and f, uncorrected, 400 particles) PS-DVB

38 particles, and $3 \mu \mathrm{m}$ PSLs (g, h, and $\mathbf{i}$, corrected, 2396 particles). 


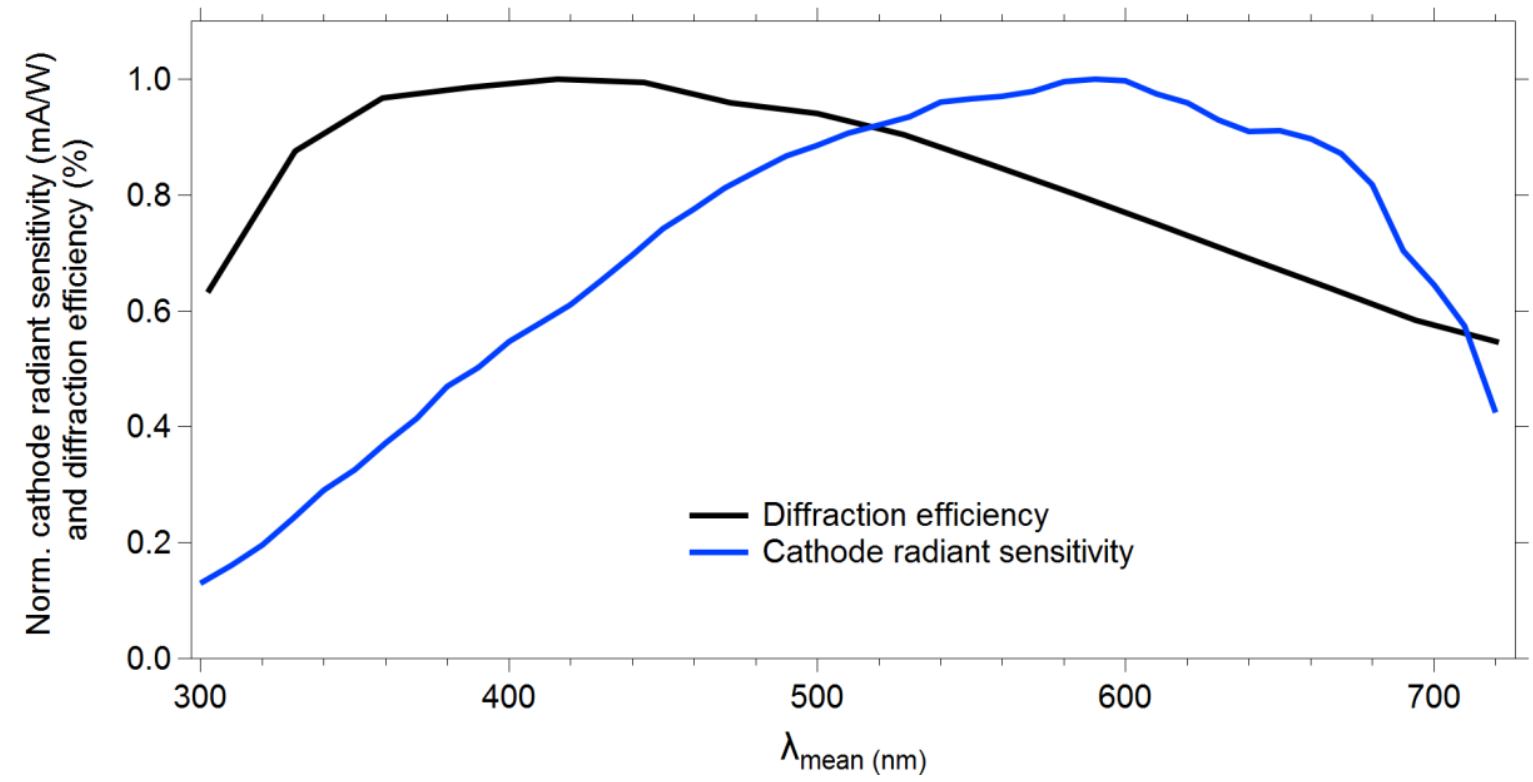

39 Figure S8. Normalized cathode radiant sensitivity of the PMT and diffraction efficiency of the 40 grating. The cathode radiant sensitivity multiplied by the diffraction efficiency results in the 41 theoretical detector responsivity shown in Figure 6. (Data courtesy: Hamamatsu). 


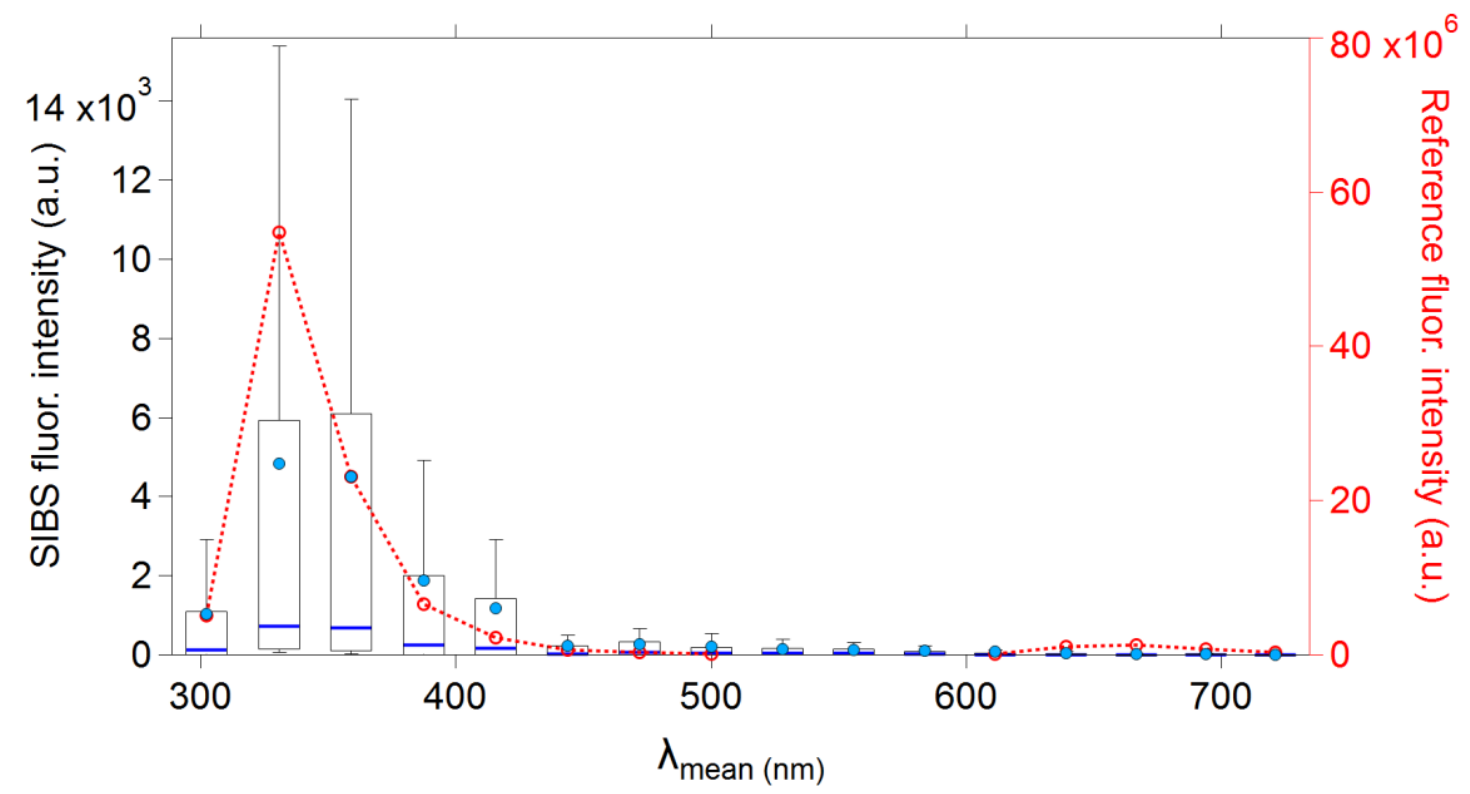

42 Figure S9. Uncorrected fluorescence spectra of tryptophan at Xe1 in a size range between 1 $432 \mu \mathrm{m}$. 
(a) NAD

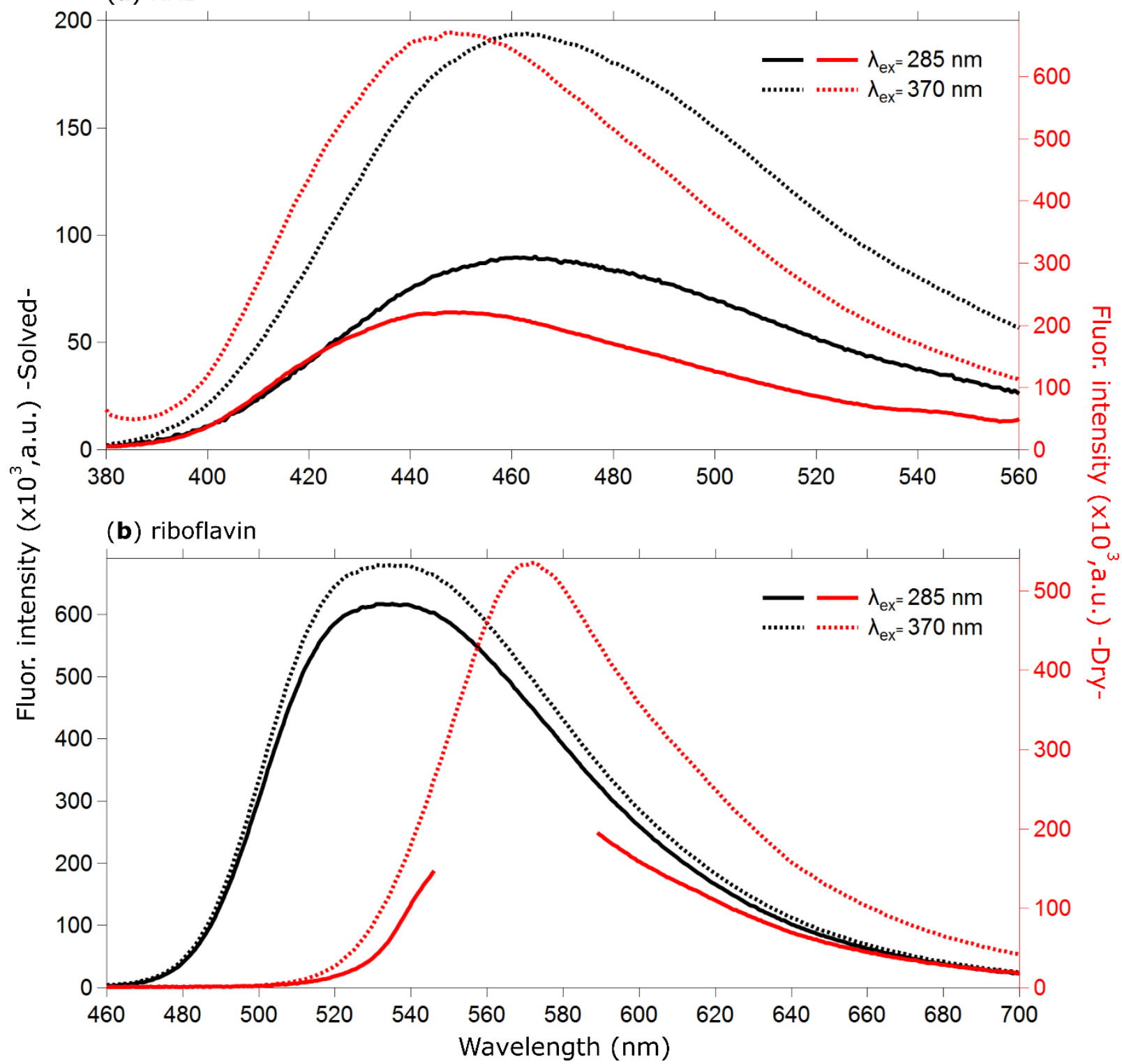

44 Figure S10. Dry vs. solved. Shown are reference spectra for NAD (a) and riboflavin (b) in dry

45 and solved state. Data coinciding with $2^{\text {nd }}$ order elastic scattering were removed (b, red solid 46 line). Peak maxima: NAD (dry): 448 nm, NAD (solved): $463 \mathrm{~nm}$, riboflavin (dry): $572 \mathrm{~nm}$, 47 riboflavin (solved): $\sim 535 \mathrm{~nm}$. 


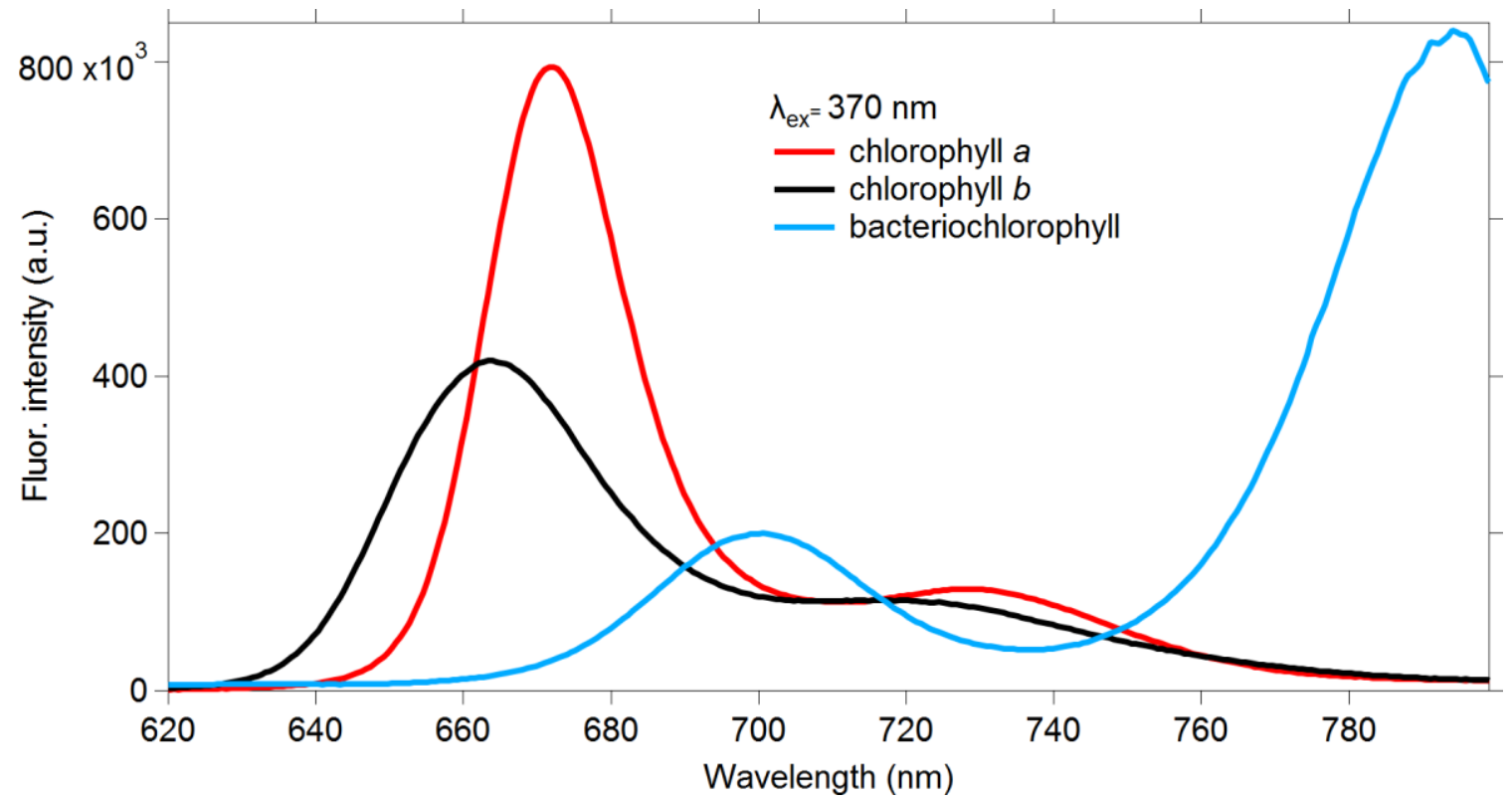

48 Figure S11. Fluorescence spectra of different chlorophyll types. Shown are reference spectra 49 for chlorophyll $a, b$, and bacteriochlorophyll at $\lambda_{\mathrm{ex}}=370 \mathrm{~nm}$. 
(b) Xe1: Ethanol

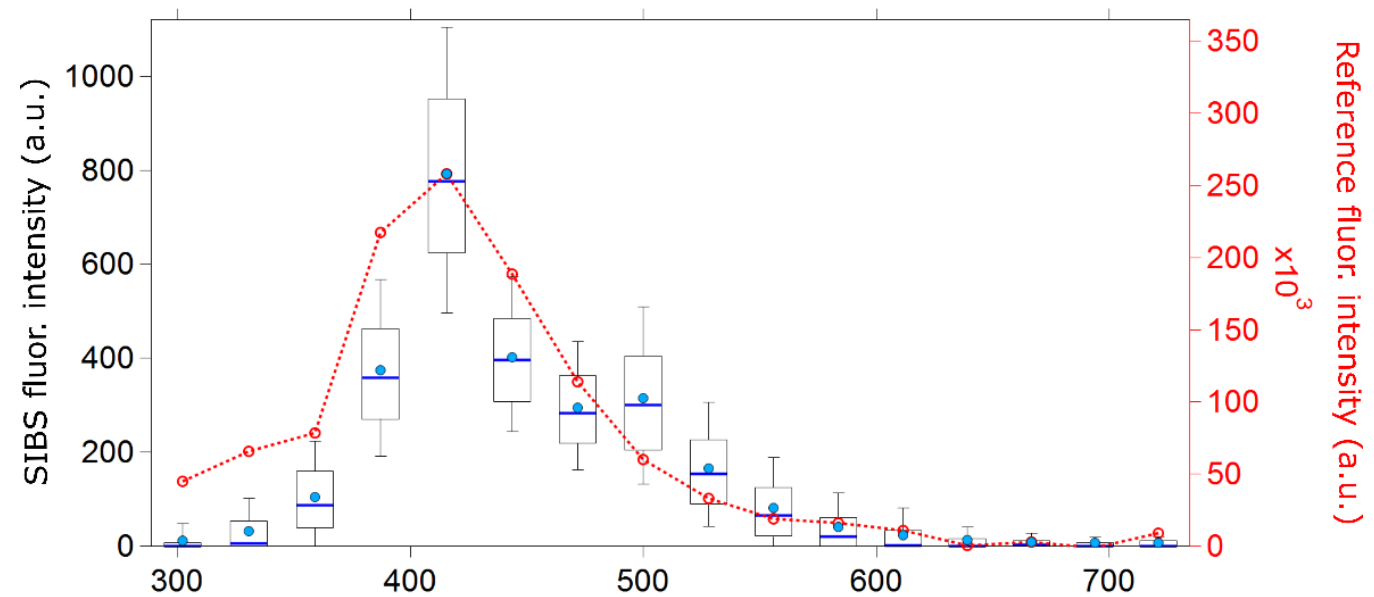

(c) Xe2: Ethanol

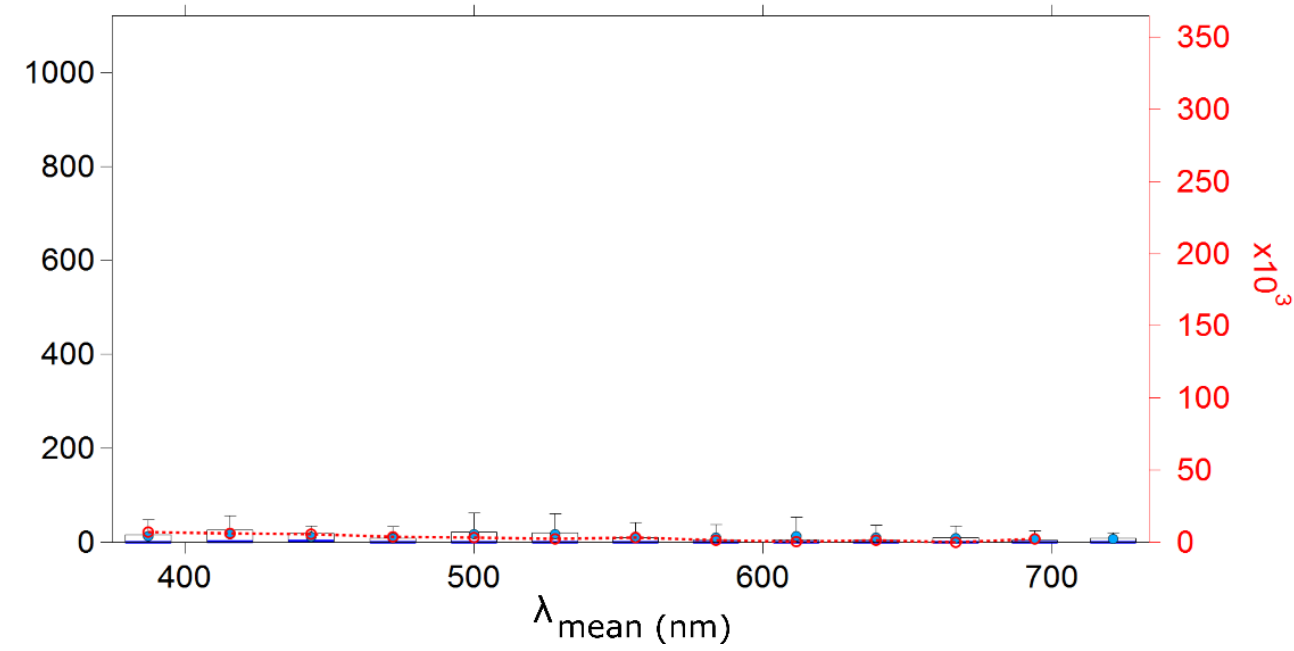

69 Figure S12. Fluorescence spectra of ethanol artefact. Highlighted are fluorescence spectra of 70 bacteriochlorophyll at Xe1 (a) and uncorrected spectra of ethanol, after being vortexed for 15 $71 \mathrm{~min}$ in nebulizer plastic bottles, at $\mathrm{Xe1}$ (b) and $\mathrm{Xe} 2$ (c). Since no distinct fluorescence signal 72 is detectable at $\mathrm{Xe} 2$ (c), the fluorescence emission of chlorophyll $a, b$ and bacteriochlorophyll 73 is considered to be unaffected. 


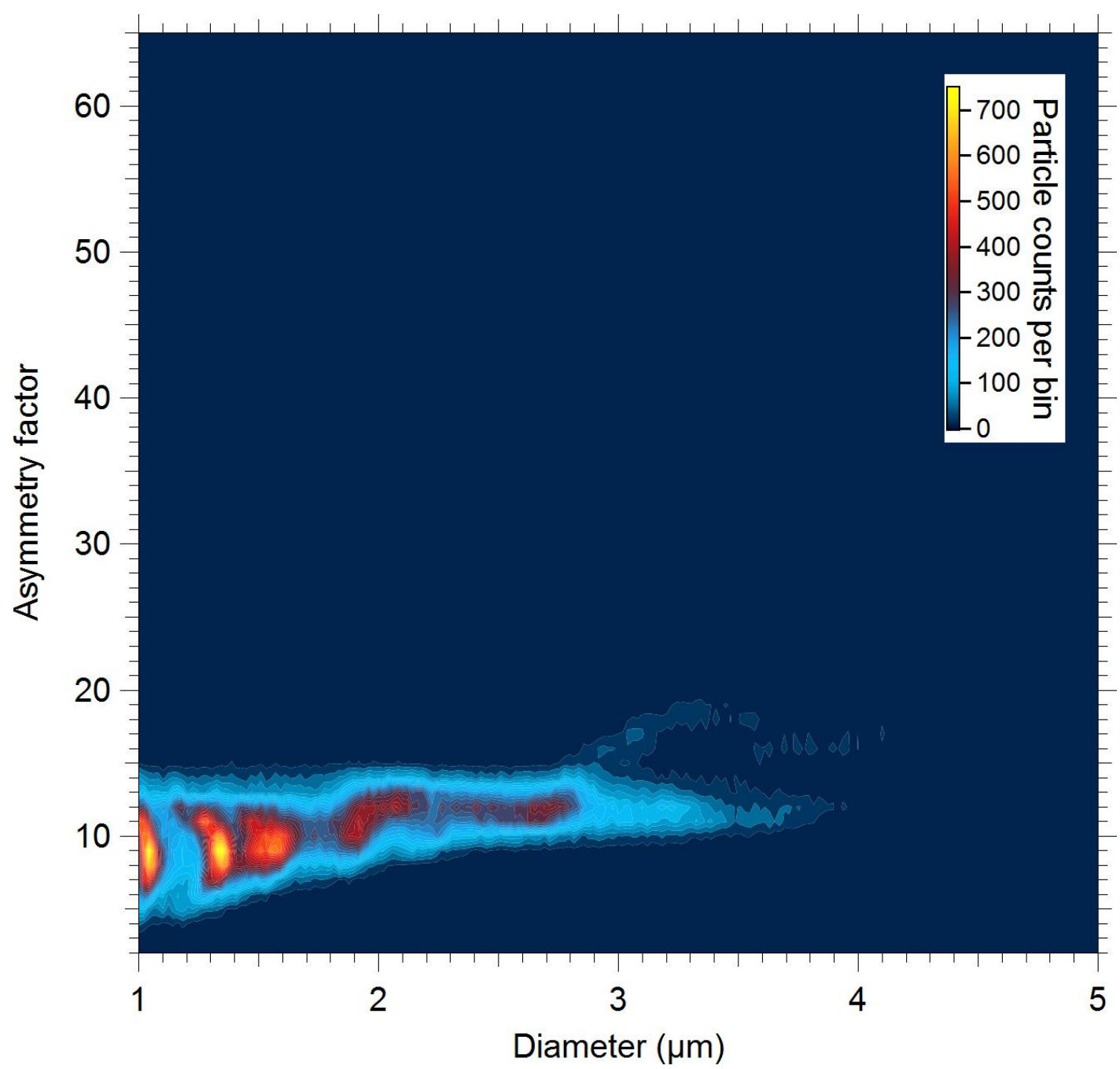

74 Figure S13. Particle asymmetry of ultrapure water droplets (163178 particles) displayed as 75 particle density histogram. 
(a) Xe1: Single particle spectra

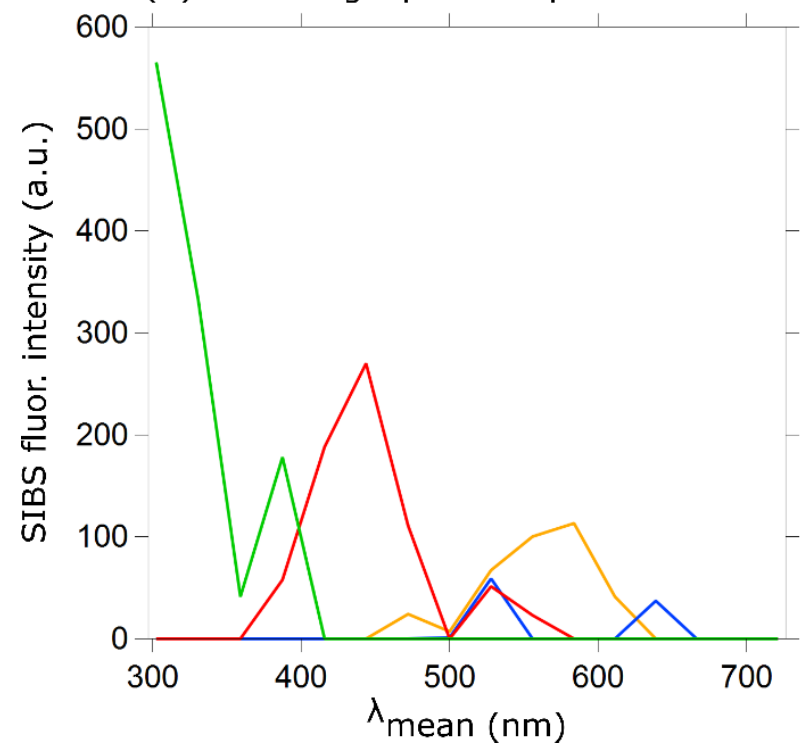

(b) Xe2: Single particle spectra

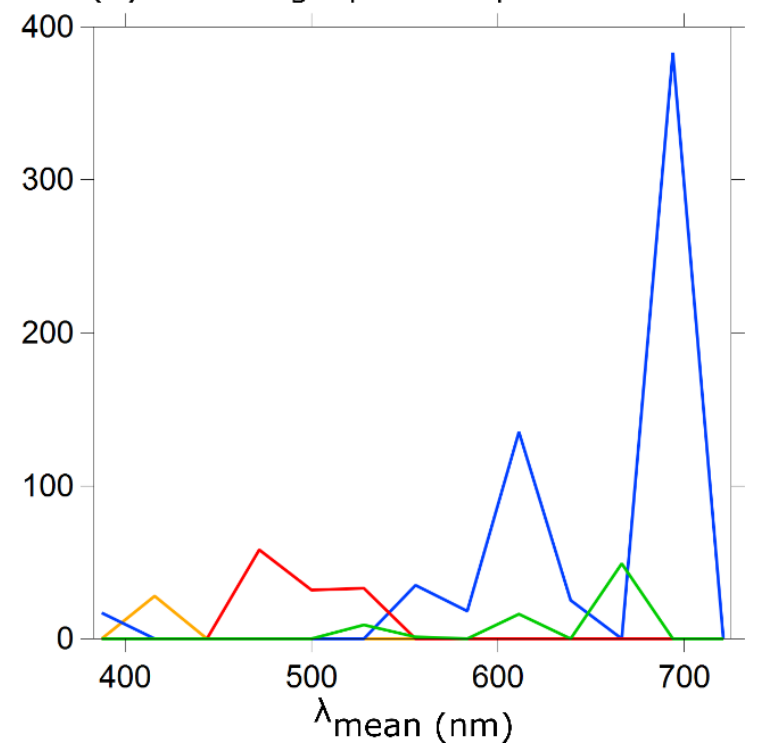

76 Figure S14. Exemplary fluorescence spectra of single ambient particles at Xe1 (a) and Xe2 77 (b). 